\title{
Determination of Risk Factors for Pre-Eclampsia in aTertiary Hospital of Bangladesh
}

\author{
Sabina Yeasmin ${ }^{1 *}$ \\ M Jalal Uddin ${ }^{2}$
}

'Department of Obstetrics \& Gynaecology Chattagram Maa-O-Shishu Hospital Medical College Chittagong, Bangladesh.

${ }^{2}$ Department of Community Medicine Chattagram Maa-O-Shishu Hospital Medical College Chittagong, Bangladesh.

\section{*Correspondence to:}

\section{Dr. Most. Sabina Yeasmin}

Assistant Professor

Department of Obstetrics \& Gynaecology

Chattagram Maa-O-Shishu Hospital Medical College Chittagong, Bangladesh.

Mobile : +88 01914339095

Email:drsabinah@yahoo.com

\begin{abstract}
Background: Pre-eclampsia is an idiopathic disorder of pregnancy characterized by proteinuric hypertention and still one of the important causes of maternal and fetal mortality.The identification of its predisposing factors before and during early stage of pregnancy will help in reducing the mortality. Objective:The objective of the present study is to determine the risk factors for pre-eclampsia among pregnant women in a tertiary level hospital. Methods: This study was conducted in the Department of Obstetrics and Gynaecology of a tertiary care hospital in Chittagong, Bangladesh, from January to June 2015.A total number of 50 pregnant women with pre-eclampsia who admitted in this hospital were selected as study group.This was hospital based descriptive study. Results: Most of the partcipants were within 21-30 years of age group and mean age $24.06 \pm 3.71$. The factors that were found to be significant predictors of risk for development of PE were primigravida, low socioeconomic condition,family history of PE \& hypertension, past history of PE and hypertention, past history of diabetes mellitus was also associated with development of PE.
\end{abstract}

Key words: Pre-eclampsia; Riskfactors; Primigravida.

\section{INTRODUCTION}

Pre-eclampsia (PE) is an idiopathic disorder of pregnancy, characterized by proteinuric hypertention ${ }^{1}$. ISt is still one of the important causes of maternal and fetal mortality ${ }^{2}$. WHO estimates incidence of pre-eclamsia, to be seven times higher in developing countries (2.4\% of live birth) than in developed countries $(.4 \%)^{3}$. In Bangladesh, the incidence of pre-eclampsia is alarmingly high,about $20 \%$ of maternal death associated with $\mathrm{PE}$ and eclampsia ${ }^{4}$. PE is a multisystem disorder of unknown etiology, development of hypertention with proteinurria after the $20^{\text {th }}$ week of gestation in a previously normotensive and nonproteinuric patient ${ }^{5}$. It causes abortion, prematurity,intrauterine growth retardation and still birth ${ }^{6}$.

Proper antenatal care remains the important part of prevention.Estimating each Woman's individualized risk allow antenatal surveillance tobedirected at those women, who are most likely to develop pre-eclampsia.Such care leads to early diagnosis and intervention, both in terms of feto-maternalmonitoring and timing of delivery.Hence there is aneed to develop an integrated model for the estimation of patient specific risk factors for the development of preeclampsia on the basis of maternal demographic, socio-economic, obstetrics, nutritional and anthropometric parameters ${ }^{7}$.

Therefore, we conducted the study to determine the risk factors of PE by directly collecting the data using questionnaire schedule fromadmitted cases of PE patients who had given the consent. 


\section{MATERIALS AND METHODS}

The study was conducted in Obstetrics and Gynaecology depertment of a tertiary care hospital in Chittagong, Bangladesh from January to June 2015 for aperiod of 6 months. It was a hospital based descriptive study. A total number of 50 pregnant women with PE who admitted in this hospital and given consent were included in this study. Thorough history was taken followed by relevant clinical examination and some baseline investigations were done Height was measured and pre-pregnancy weight was noted.For renal function urine for protrein,blood for urea, creatinine and uric acid estmation were done. All informations were recorded in a pre-tested mixed type questionnaire.

This study was approved by institutional Review board and informed consent was received from all the participants.

\section{RESULTS}

In this study most of the patients belonged to21-30 years of age group (72\%). This study revealed that, $52 \%$ women were from low socioeconomic status.Education level, occupation, type of family were not significantly associated with development of preeclamsia (Table-1).

Table 1: Distribution of age and socio-economic risk factors.

$\begin{array}{lrr}\text { Variables } & \text { No. of patients } & (\%) \\ \text { Age in years } & & \\ \leq 20 & 6 & (12 \%) \\ 21-30 & 36 & (72 \%) \\ 31-40 & 8 & (16 \%) \\ \text { Mean } \pm \text { SD } & 24.06 \pm 3.71 & \end{array}$

\section{Education level}

Illiterate

Upto SSC

Upto HSC

Graduation and above

\section{Occupation}

Housewife

Service holder

\section{0}

$(80 \%)$

Family income/month*

SEC $-\mathrm{A}>\mathrm{BDT}$ 30,000

SEC-B $>$ BDT 15000-BDT 30,000

SEC - C BDT 6000-BDT1 5000

SEC - D $<$ BDT 6000

\section{Type of family}

Nuclear

Joint and extended
Table 2 : Showing obstetrics risks factors.

\begin{tabular}{lcc} 
Variables & Number of patient & $(\%)$ \\
Parity & 32 & $(64 \%)$ \\
0 & 18 & $(36 \%)$ \\
1 & & \\
Gravidity & 31 & $(62 \%)$ \\
Primi & 19 & $(38 \%)$ \\
Multi & & \\
Number of feotus & 1 & $(2 \%)$ \\
Twins & 49 & $(98 \%)$ \\
Singletone & & \\
Duration between present and previous pregnancy \\
$<1$ year & 6 & $(12 \%)$ \\
$1-5$ years & 40 & $(80 \%)$ \\
$\geq 5 y e a r s$ & 4 & $(8 \%)$ \\
History of abortion before this pregnancy & \\
Yes & 8 & $(16 \%)$ \\
No & 42 & $(84 \%)$ \\
Bad obstetric history & & \\
Yes & 1 & $(2 \%)$ \\
No & 49 & $(98 \%)$ \\
\hline
\end{tabular}

Primigravida constituted $62 \%$ of total PE cases. Twin pregnancy, duration between present and previous pregnancy, history of abortion and bad obstetrics history were not significantly associated with development of preeclampsia (Table 2).

Table 3 : Showing past and family history risk factors.

$\begin{array}{lrr}\text { Variables } & \text { Number of patient } & (\%) \\ \text { Past history of Hypertention } & & \\ \text { Yes } & 10 & (20 \%) \\ \text { No } & 40 & (80 \%) \\ \text { Past history of Diabetes Mellitus } & & \\ \text { Yes } & 2 & (4 \%) \\ \text { No } & 48 & (96 \%) \\ \text { History of Hypothyroidism } & 1 & (2 \%) \\ \text { Past history of preeclampsia } & & \\ \text { Yes } & 19 & (38 \%) \\ \text { No } & 31 & (62 \%) \\ \text { Past history of Eclampsia } & & \\ \text { Yes } & 1 & (2 \%) \\ \text { No } & 49 & (98 \%) \\ \text { Family history of Hypertention } & & \\ \text { Yes } & 30 & (60 \%) \\ \text { No } & 20 & (40 \%) \\ \text { Family history of Preeclamsia } & & \\ \text { Yes } & 31 & (62 \%) \\ \text { No } & 19 & (38 \%) \\ \text { BMI } & & \\ \geq 25 & 29 & (58 \%) \\ <25 & 21 & (42 \%)\end{array}$

Past history of PE, hypertention, diabetes, hypothyroidism, family history of PE,hypertention were associated with development of PE. Women with higher body mass index (>25)were risk in development of PE (Table 3 ). 


\section{DISCUSSION}

The study was aimed to find the risk factors for development of PE.The risk factors identified that influence the development of preeclamsia included extremes of maternal age,race,socioeconomic factors,change of paternity, twin pregnancy, nulliparity,increased birth interval, increased BMI, increased systolic and diastolic blood pressure inearly pregnancy, increased rate of weight gain during pregnancy and the presence of gestational diabetes $8,9,10$.

In this study incidence of PE was high among 21-30 years of patient.Similar study by Bej Puny et al and Sultana $\mathrm{R}$ et $\mathrm{al}^{6,11}$. But many other studies i.e.Parmar $\mathrm{M} \mathrm{T}$ et al showed that teenage pregnancy was the risk factors ${ }^{12}$.

The study reveals that preeclamsia was high in primigravid patient.Similar study by Sultana R et al, Parmar M T et al and Odegard et al where they showed nulliparity as risk factors for preeclampsia.Study by Bhattacharya S \& Duckitt et al also reported that primigrvida was a risk factor for pre-eclampsia $\&$ eclampsia $^{11-15}$.

It was observed in our study that PE was high in women with lower socio-economic status having poor antenatal care. The reason could be illiteracy, they come to the hospital only in case of serious problems \& in a large majority of patients PE remain asymptomatic \& remits spontaneously, since diagnosis of PE often missed.This is consistent with literature by Parmar M T et al \& Yucesoy G et al ${ }^{12-16}$.

In this study $19(38 \%)$ of the patient (Though percentage seems less but all multigravid patients hadthe history) were having $\mathrm{H} / \mathrm{O} \mathrm{PE}$ in previous pregnancy,most of the PE cases also having family H/O PE \& obesity. Similar results observed in a study by Parmar M T et al \& S Ganesh Kumar ${ }^{12,17}$ most of the cases were having family $\mathrm{H} / \mathrm{O}$ hypertention , such results shown by Konar $\mathrm{H}^{12,17,5}$
The family $\mathrm{H} / \mathrm{O}$ convulsions, i.e eclampsia could be elicited easily while history of blood pressure was difficult to recall by patients. Severe preeclamsia is of familial origin,as has been shown by many investigators ${ }^{18}$. There is primary evidence of the genetic component in the determination of disease and implies that it would be good a practice to enquire routinely the family history of severe preeclamsia to obtain early warning of possible "high risk" cases.

It was observed that, $20 \%$ and $2 \%$ of cases had a past history of hypertention and diabetes mellitus respectively .Such study shown by Bej Puny ${ }^{6}$. Ros et al quoted that in diabetic women, high levels of plasma triglycerides causes endothelial cells to accumulate triglycerides leading to endothelial cells dysfunction that predisposes to develop high blood pressure ${ }^{9}$.

The limitation of this study were first it was a hospital based study hence can't be generaliged to the whole population. Second, there might be a chance of recall bias among the patient.

\section{CONCLUSION}

To conclude, primigravida ,past history of PE , hypertention, diabetes mellitus family history of PE ,hypertention and obesity are the major risk factors for PE.A checklist containing all the risk factors is to be asked routinely in antenatal checkup to prevent the development of PE.

\section{DISCLOSURE}

Both the authors declared no competing interest. 


\section{REFERENCES}

1. Edmonds D.K.Hypertensive disorders,Dewhurst's text book of obstetrics and gynaecology. 2012;8:101

2. Sibai BM, Gordon T, Thom E. Risk factors for preeclamsia in healthy nulliparous women: A prospective multicentre study. The National institute of child Health and Human Development Network of Maternal- Fetal Medicine Units.Am J Obstet Gynecol.1995;172:642-648.

3. WHO, Make every mother and child count, in The world health report 2005, World Health organization, Geneva, Switzerland, 2005.

4. Landscape Analysis on Pre-eclamsia and eclamsia in Bangladesh 2015.Dhaka: Population council.

5. Konar H.Hypertensive disorders in pregnancy, D.C. Dutta's text book of Obstetrics. 2015;8:255.

6. Bej puny, Chhabra P, Sharma A.K. Guleria K.Determination of Risk factors for Pre-eclamsia and Eclamsia in a Tertiary Hospital of india:A case control Study. J of Family Medicine and primary care. 2013;2(4):371-375.

7. Yu Ck, Smith GC, Papageorghiou AT, Cacho AM, Nicolaides KH,Fetal Medicine Foundation Second Trimester screening Group.An integrated model for the prediction of preeclamsia using maternal factors and uterine artery Doppler velocimetry in unselected low-risk women.Am J Obset Gynecol. 2005;193:429-436.

8. Sibai BM, Ewell M, Lvine RJ, Klebanoff MA, Esterlitz J, Catalano PM, et al.Risk factors associated with preeclamsia in healthy nulliparous women. The Calcium for Preeclamsia Prevention (CPEP) study group. Am J Obster Gynecol. 1997;177:1003-1010.

9. Ros HS, Cnattingius S, Lipworth L. Comparison of risk factors for preeclamsia and gestational hypertention in a population-based cohort study. Am J Epidemiol. 1998;147:1062-1070.

10. SK jaerven R, Wilcox AJ, Lie RT.The interval between pregnancies and the risk of pereeclamsia N EngI J Med. 2002;346:33-38

11. Sultana R, Ahmed S, Sultana N, Karim S.M.F, Atia F.Association of Serum Uric Acid with Preeclamsia:A Case control study.Delta Medcal College J (Bangladesh). 2013;1(2):46-50.

12. Parmar M. T, Solanki H.M, Gosalia V. Study of risk factors of perinatal death in pregnancy induced hypertention. National Journal of Community Medicine. 2012;3(4):703-707.

13. Odegard RA, Vatten LJ, Nilsen ST, Salvasen KA, Austgulen R. Risk factors and clinical manifestations of preeclamsia. Br J Obstet gynecol. 2002; 107:1410-1416.

14. Bhattacharya S. Pregnancy induced hypertension and prior trophoblastic exposure.Ind J Obset Gynaecol. 2004;54(6): 568-570.

15. Duckitt K, Harrington D.Risk factors for Preeclamsia at antenatal booking: Systematic review of controlled studies.BMJ 2005; 330:565-577.

16. Yucesoy G. et al. Maternal and perinatal outcome in pregnancies complicated with hypertensive disorder of pregnancy: A seven year experience of a tertiary care centre.Arch Gynecol Obset.2005;273(1):43-49.

17. S Ganesh Kumar et al. Determinants of Pre-eclamsia:A case-control study in a district hospital in South India.Indian J of Community Medicine. 2010; 35(4):502-505

18. Cincotta RB, Brennecke SP. Family history of Pre-eclamsia as a predictor for Pre-eclamsia in primigravidas.Int J Gynaecol Obstet 1998;60:23-27. 